\title{
ОСОБЕННОСТИ ИССЛЕДОВАНИЙ \\ СЕКСУАЛЬНОЙ ОРИЕНТАЦИИ: \\ ДЕМОГРАФИЧЕСКИЕ ХАРАКТЕРИСТИКИ \\ РОССИЙСКИХ ГОМОСЕКСУАЛОВ
}

\section{ДМИТРИЙ ТОЛКАЧЕВ}

\begin{abstract}
В демографии как один из видов демографического поведения рассматривается сексуальное. Сексуальная ориентация - наиболее широкий термин, предполагающий несколько концепџий, от которых зависит дизайн исследования. Сексуальное поведение, сексуальная идентичность и сексуальное влечение требуют различных исследовательских подходов и способов измерения.

В настоящей статье предложен обзор современных направлений в концептуализации и измерении сексуальной ориентации, а также приведено описание демографических данных, полученных в ходе опроса российских гомосексуалов ( $n=390)$.

В исследованиях сексуальности в социальных науках можно выделить 3 основных подхода: эссенциалистский, конструтивисткий и квир-подход. Они различаются пониманием истоков (гомо)сексуальности и трактовками ориентации (как идентичности, поведения или влечения). В статье предлагаются варианты формулировок вопросов для измерения сексуальной ориентации 8 рамках трёх подходов, а также обзор методологических ограничений - проблемы выборки и определения генеральной совокупности.
\end{abstract}

Мы приводим результаты общероссийского ЛГБТ-опроса и даём описание данньх о российских гомосексуалах (геях и лесбиянках). Полученные данные позволяют охарактеризовать возраст осознания и принятия сексуальной ориентации, возраст сексуального дебюта, опьт каминг-аута родственникам, друзьям и коллегам, отношения с родственниками, опыт насилия и дискриминации, доверие органам власти.

Ключевые слова: сексуальная ориентация, ЛГБТ, гомосексуальность, демография сексуальности, квир, российские гомосексуаль.

\section{ДЕМОГРАФИЯ И СЕКСУАЛЬНОСТЬ}

В демографии как один из видов демографического поведения рассматривается сексуальное. В современном мире прослеживается чёткое различение сексуального, матримониального и репродуктивного поведения и наблюдается дестандартизация демографических событий. Демографы первоначально фокусировались больше на сексуальном поведении, чем на сексуальной идентичности или сексуальных желаниях (Baumle 2013).

ДМИТРИЙ СЕРГЕЕВИЧ ТОЛКАЧЕВ (dtolkachev@hse.ru), НАЦИОНАЛЬНЫЙ ИССЛЕДОВАТЕЛЬСКИЙ УНИВЕРСИТЕТ «ВЫСШАЯ ШКОЛА ЭКОНОМИКИ», РОССИЯ.

СТАТЬЯ ПОСТУПИЛА В РЕДАКЦИЮ В МАЕ 2021 Г. 
Большое внимание по-прежнему уделяется семейным отношениям (Гурко 2008; Исупова 2020; Митрофанова 2020), репродуктивному здоровью и практикам (Martin 2015; Чурилова, Чумарина 2014; Гудкова 2019; Осипова 2020), рискованному сексуальному поведению и инфекциям, передаваемым половым путём (Meyer, Northridge 2007; Демедецкая, Денисов, Лапицкая 2019; Астрелин 2020).

Исследования гомосексуальности имеют не очень долгую историю. Аманда Бомл (Baumle 2013) показывает, что в демографических журналах к 2006 г. написано за 3 десятилетия 519 работ, содержащих слова «сексуальная ориентация», «лесбиянка», «гей» и «гомосексуал», а к 2013 г. их количество увеличилось на 153. Основными темами таких исследований были репродуктивное здоровье, юридическое признание однополых союзов и миграционные исследования.

Сексуальная ориентация становится предметом демографических исследований с разных сторон: описание ЛГБТ ${ }^{1}$-популяции (Black et al. 2000); анализ юридического признания однополых пар и демографические последствия легализации браков, структуры семьи (показателя партнерств и наличия детей) (Festy 2006; Baumle, Compton, Poston 2009), миграции, результатов труда (заработка) и экономических различий (Baumle, Poston 2011). оссийские исследователи фокусировались на теоретических и методологических подходах к квир-теории и ЛГБТ-исследованиям (Кон 2010; Кондаков 2014; Градинари 2015) с преимущественным использованием качественных методов с целью описания практик и «жизненных миров» (Nartova 2007; Stella 2015; Zdravomyslova, Temkina 2012), а также на результатах закона о пропаганде (Кондаков 2014; Wilkinson 2014; Tolkachev, Vasileva 2019) и влиянии консервативного поворота на регулирование сексуальностей (Makarychev, Medvedev 2015; Riabov, Riabova 2014), однако не уделяли особого внимания описанию демографических характеристик.

Исследователи разделяют сексуальную ориентацию и гендерную идентичность, в рамках данной работы мы фокусировались только на сексуальной ориентации. Ключевой исследовательский вопрос: какие демографические особенности гомосексуальных россиян можно выявить посредством онлайн-опроса? Главной целью работы является описание демографических характеристик российских гомосексуалов. Для этого необходимо описать возраст осознания и принятия сексуальной ориентации, возраст сексуального дебюта, опыт каминг-аута родственникам, друзьям и коллегам, отношения с родственниками, опыт насилия и дискриминации, доверие органам власти.

Сексуальная ориентация - наиболее широкий термин, предполагающий несколько концепций, от которых зависит дизайн исследования. Сексуальное поведение, сексуальная идентичность и сексуальное влечение требуют различных исследовательских подходов и способов измерения.

\footnotetext{
1 Здесь и далее ЛГБТ (лесбиянки, геи, бисексуалы, транс-персоны) используется как зонтичный термин в рамках исследования сексуальной ориентации.
} 


\section{КОНЦЕПТУАЛИЗАЦИЯ СЕКСУАЛЬНОЙ ОРИЕНТАЦИИ}

В исследованиях сексуальности можно выделить 3 основных подхода: эссенциалистский, конструктивистский и квир-подход. Эссенциалисты рассматривают (гомо)сексуальность как черту человека, а значит, её можно найти в любой культуре и в любое время (Ball 2001). Эссенциалистский подход возник как ответ на объяснение гомосексуальности как феномена «против порядка природы». Здесь исследователи ставили следующие задачи: исследовать животный мир в поисках объяснения гомосексуального поведения у животных и исследовать природу человеческой гомосексуальности с точки зрения биологических процессов (Halwani 1998). Механизмы, объясняющие вариацию сексуальной ориентации, включают гормональные и генетические основания, а также механизмы несоциальной среды. В последнем случае речь идёт о порядке рождения братьев (fraternal-birth order effect, FBOE), что объясняется биологическими причинами, но доступно для измерения в рамках опросов. Порядок рождения (FBOE) - эволюционное объяснение причин гомосексуальности. Исследователи изучали не только последовательность рождения братьев, но и их сексуальные роли, чтобы объяснить гомосексуальность младших братьев (Blanchard 2018; Wampold 2018).

Социальные конструктивисты полагают, что (гомо)сексуальность следует анализировать по-разному в определенных культурах и в определенные периоды времени, следовательно, сексуальность следует рассматривать как шкальный, а не бинарный концепт (Фуко 1996; Butler 1997; 2006; Halwani 1998). Дискуссия между конструктивистами и эссенциалистами привела к рождению третьего, иного подхода к определению природы человеческой сексуальности - квир-теории.

Квир (в дословном переводе «странный, чудной») первоначально - форма оскорбления, уничижительный термин для людей с однополым влечением. Квир на сегодняшний момент используется в качестве обобщающего термина для негетеросексуалов. Квир-активизм, квир-политика и квир-теория разделяют непринятие политики идентичности. Основной принцип квир-теории - устранение чрезмерно упрощенных бинарных категорий (таких как гетеросексуальный/гомосексуальный, мужчина/женщина, Восток/Запад), что рассматривается как необходимая ликвидация бесполезных, обобщающих категорий, которые препятствуют более детальному анализу конструирования сексуальности и гендера.

Различие в трактовках идентичности - основное отличие квир-подхода. Квирность это идентичность без сущности, т. е. отсутствие необходимости на что-то ссылаться. Стабильность и естественность в данном подходе подвергается сомнению, в том числе и эссенциалистские (заданные природой, врождённые) характеристики. Сторонники теории идентичности (конструктивисты) утверждают, что если сексуальная ориентация существует, то определяется она самим человеком, и рассказывая о «выходе из чулана», совершая камин-аут, человек «утверждает свою волю противостоять угнетению» (Crawley, Broad 2008). Следовательно, сексуальная ориентация считается подлинной и фиксированной. Сторонники же квир-подхода указывают, что никакой подлинной идентичности не существует, а сама «подлинность» формируется властным дискурсом (Crawley, Broad 2008). 
Сексуальная ориентация может быть нефиксированной, т. е. речь идёт о флюидности сексуальности. Идея флюидности исходит из концепции шкалы Кинси (Drucker 2010). Согласно исследованиям Кинси сексуальность можно разделить на 7 значений шкалы, поэтому сексуальность не бинарный, а шкальный концепт. Если значение «0» - это исключительная гетеросексуальность, а значение «6» - исключительная гомосексуальность, то между данными показателями существует значительный промежуток. И в течение всей жизни человек может следовать различным сексуальным практикам ${ }^{2}$. «Гей - преимущественно идентичность, квир - это форма вызывающе непослушного анализа» (Bartle 2015: 532). Идентичность предполагает, что определение (себя) геем или лесбиянкой это «объективные, эмпирические категории, регулируемые эмпирическими правилами доказывания (empirical rules of evidence)» (Bartle 2015: 532), а значит, идентичности требуют стабильности и сходства. Квир (как форму анализа) интересуют нестабильность и различия, радикальность и перформативность экспериментального восприятия и происхождения.

Отличная от гетеросексуальной идентичность конструируется в процессе камингаута. Каминг-аут (coming out) как добровольное, публичное раскрытие (гомо)сексуальной идентичности включает несколько этапов, основанных на психологических факторах, сексуальных и романтических практиках, самоопределении (характеристиках себя), (гомо)социальных связях (Cass 1984; Milton, MacDonald 1984). В рамках опроса авторов статьи интересует возраст наступления двух этапов - осознания (awareness) и принятия (behavioral acceptance) идентичности, а также возраст сексуального дебюта. С точки зрения совершения каминг-аута - открытость для родственников, друзей и коллег.

Сексуальные практики также важны для понимания гомосексуальной идентичности. Исследователи сексуальных ролей, с одной стороны, находят эмпирическое подтверждение концепций в исследованиях на выборке гомосексуальных мужчин (Grov, Parsons, Bimbi 2010; Pachankis et al. 2013), с другой - дихотомические категории бутч/фем и актив/пассив подвергаются критике как чрезмерно упрощенные (Pachankis et al. 2013). С точки зрения сексуальных практик и идентичности среди гомосексуальных мужчин используются категории «пассив», «универсал», «актив» для описания сексуальной роли, что является не только позицией (инсертивной или рецептивной) во время анального секса, но и «позволяет участвовать [в конструировании] дискурса власти и удовольствия во время секса» (Pachankis et al. 2013: 1242). На позиции влияет раса и этническая принадлежность, страна рождения, образование, класс, восприятие феминности и маскулинности и гендерные стереотипы, восприятие тела, особенно размер полового члена (Wei, Raymond 2011; Grov, Parsons, Bimbi 2010). Стабильность и изменение сексуальной позиции определятся идеограифическими, психосоциальными и социокультурными факторами (Pachankis et al. 2013: 1243), последние могут оказывать влияние на становление идентичности.

Различия в определении сексуальной ориентации накладывают методологические ограничения: итоговый процент гомосексуальной популяции будет меняться в зависимости от разных подходов (Poston, Chang 2015). Далее мы предлагаем рассмотреть способы

\footnotetext{
${ }^{2}$ О сложности такого подхода см. (Vrangalova, Savin-Williams 2012).
} 
измерения сексуальной ориентации, чтобы перейти к описанию исследования российских гомосексуалов.

\section{ИЗМЕРЕНИЕ СЕКСУАЛЬНОЙ ОРИЕНТАЦИИ}

Выделим 3 варианта, с помощью которых можно выявить сексуальную ориентацию в самостоятельно заполняемых анкетах: самоидентификация (идентичность), сексуальное поведение и сексуальное влечение (Sell 2007).

Разные подходы к изучению сексуальной ориентации требуют соответствующих формулировок вопросов. Корректная оценка ЛГБТ-популяции будет зависеть от целей исследования и подхода к определению сексуальной ориентации (Meyer, Wilson 2009), а также может зависеть от подхода к сексуальности с учётом специфики конкретной страны (Diamond 1993).

Попытка определения доли гомосексуального населения, начавшаяся с Кинси, до сих пор является важным исследовательским вопросом. Определение «генеральной совокупности» исходит из бинарного или шкального определения сексуальности, но статичного её понимания: сексуальность фиксирована и не меняется с течением времени. Но современный квир-подход предлагает рассматривать сексуальность как динамичную, флюидную категорию, т. е. сексуальная ориентация может меняться с течением жизни. Например, бисексуальная персона может вступать в гетеросексуальные или гомосексуальные отношения в различные периоды жизни. ЛГБТ-выборки делают невозможной генерализацию (Meyer, Wilson 2009). Основная проблема генерализации в том, что ЛГБТ-популяция не была должным образом перечислена (Blair 1999); современные исследователи указывают, что генеральная совокупность - это 3-10\% от всего населения в зависимости от формулировки вопроса (обзор см. (Singer, Deschamps 2017)).

Генерализация затруднена также потому, что, во-первых, ЛГБТ-люди определяют себя как часть сообщества только после каминг-аута, т. е. процесса публичного раскрытия идентичности (Eliason, Schope 2007), а во-вторых, потому что сексуальная идентичность может отличаться от сексуальных практик. Люди могут сообщать об однополом сексуальном поведении или влечении, не имея идентичности ЛГБТ (Laumann et al. 1994).

В случае исследований идентичности наиболее подходящей формулировкой вопроса может быть (Durso, Gates 2013): «Вы считаете себя: гетеросексуалом или гетеросексуалкой, геем или лесбиянкой, бисексуалом или бисексуалкой» или «Что из нижеперечисленного лучше описывает Вас». Другой вариант: «Что лучше описывает вашу идентичность» (Pachankis et al. 2013: 1243). Если требуется исследование гомосексуальной и гетеросексуальной популяции, рекомендуется не включать в вопрос такие термины, как «сексуальная ориентация» или «идентичность», так как это может сбить столку респондентов, не знакомых с данными определениями. Также мы бы рекомендовали избегать совместного использования терминов «гетеросексуал» и «гомосексуал» 
(использовать слова «геи» и «лесбиянки» вместо последнего) или добавлять определение гетеросексуальности и гомосексуальности ${ }^{3}$.

С точки зрения влечения может использоваться следующая формулировка (Durso, Gates 2013): «Люди различаются по своему влечению к другим людям. Что лучше всего описывает ваши чувства? - Привлекают только женщины. Привлекают мужчины и женщины. Привлекают только мужчины. Точно сказать не могу⿰氵⿱⿲丶丶㇒一 ». Можно также предложить разбивку на 2 вопроса: «Вы испытываете сексуальное влечение к мужчинам/женщинам? - Да. Нет» или «Вас сексуально привлекают мужчины/женщины? Да. Нет».

C точки зрения сексуального поведения нас интересуют сексуальные практики в конкретном временном интервале. Варианты вопросов могут быть следующие: «С кем вы занимались сексом в [интервал]? - Только мужчины. Только женщины. Мужчины и женщины. У меня не было секса». Другой вариант бинарного вопроса: «Был ли у Вас [интервал] секс с женщиной / мужчиной - Да. Нет».

Исследователи рекомендуют использовать термины «секс» или «сексуальный опыт» вместо «половой акт», поскольку они предполагают широкий спектр поведения. Хотя зачастую респонденты могут подразумевать под сексом только вагинальную или анальную пенетрацию и исключать остальные сексуальные практики.

С точки зрения исследования сексуальной позиции ${ }^{5}$ возможны следующие варианты (Pachankis et al. 2013: 1243; Grov, Parsons, Bimbi 2010: 791): «Я идентифицирую себя как», «Укажите предпочитаемую сексуальную позицию/роль»: «исключительно актив, преимущественно актив, универсал, преимущественно пассив, исключительно пассив» с возможным добавлением вариантов «я предпочитаю не описывать себя в таких категориях» и «я использовал такие определения ранее, но не сейчас». Другой вариант, представленный в приложениях для знакомств, на наш взгляд, более понятен респондентам: «Ваша сексуальная роль/позиция: только активная; универсальная, но больше активная; универсальная; универсальная, но больше пассивная; только пассивная».

Определение сексуальной ориентации может оказать влияние на результаты исследования. Далее мы предлагаем рассмотреть результаты опроса российских гомосексуалов.

\footnotetext{
${ }^{3}$ Особенно это актуально в российских условиях, когда люди могут путать определения гомосексуальности и гетеросексуальности. Несколько примеров: социальные эксперименты на улицах, когда россиян спрашивают, как они относятся к гетеросексуальности, а они путают это с гомосексуальностью.

${ }^{4}$ Исследователи предлагают здесь и дополнительные варианты ответов, такие как «больше всего привлекают», помимо «привлекают только». Но, на наш взгляд, они могут затруднить выбор для респондентов.

${ }^{5}$ Помимо идентичности сексуальной позиции (sexual position identity) указанные авторы предлагают вопросы о фантазиях (sexual position fantasies) и практиках частоты анального секса и позиции (anal sex frequency, anal sex position frequency).
} 


\section{РЕЗУЛЬТАТЫ ОПРОСА РОССИЙСКИХ ГОМОСЕКСУАЛОВ}

Опрос на платформе Google (Google Forms) распространялся через ЛГБТ-группы в социальных сетях и телеграм-каналах в 2020 г.

Долю российского гомосексуального населения определить практически невозможно. В рамках данной статьи мы предлагаем использовать диджитал-инструменты для определения доли гомосексуального населения через рекламные кабинеты социальных сетей. Таргетологи, которые настраивают рекламу в социальных сетях, могут настроить показ рекламы на аудитории по интересам или на подписчиков конкретных групп. Так, например, в рекламном кабинете Facebook есть отдельных вид настройки по интересам «ЛГБТ» и доля таковой аудитории в отношении ко всей рекламной аудитории составляет $10 \%$. В российской социальной сети Вконтакте нет отдельного интереса, но аудитории можно вычислить путём пересечения подписчиков на группы, которые содержат ключевые слова ЛГБТ-сообщества. Доля аудитории таких групп ${ }^{6}$ в общем числе пользователей не превышает $2 \%$. У такого подхода есть несколько важных ограничений. Во-первых, здесь учитывается только население с доступом в социальные сети и в конкретные из них (Вконтакте, Instagram, Facebook). Во-вторых, интерес к ЛГБТ-тематике не означает принадлежности к ЛГБТ-сообществу как идентичности, так и к гомосексуальным практикам. Например, это могут быть дружественные к ЛГБТ гетеросексуалы, которых интересует ЛГБТ-культура.

Вероятностная выборка (probability sample) даже в случае ЛГБТ-исследований остаётся дорогим инструментом, что вынуждает ограничиваться географией (например, зоны проживания - gay neighborhoods) или методами сбора данных (например, random-digit dialing) (Meyer, Wilson 2009). В случае России вероятностная выборка неосуществима, так как сложно выявить гей-районы или проводить телефонные опросы. Невероятностная выборка (non-probability sample) позволяет избежать дилемм, с которыми сталкиваются исследователи ЛГБТ-популяции: сложность определения самой популяции, сложность доступа, отрицание идентичности (как следствие дискриминации) и уход от ответов на деликатные вопросы, подход к определению сексуальной ориентации (Meyer, Wilson 2009). Стратегии рекрутирования могут предполагать выборку в специальных общественных местах, метод снежного кома, метод управляемой респондентами выборки (respondentdriven), онлайн-методы и другие (Meyer, Wilson 2009).

Онлайн-методы имеют несколько ограничений (Meyer, Wilson 2009; Мавлетова 2012). Во-первых, это проблема доступа к Интернету. Во-вторых, персональные и социальные характеристики, а также форма опроса могут влиять на заполнение анкет. С точки зрения ЛГБТ-исследований и сензитивности темы (особенно в российском контексте отношения к гомосексуальности) главным преимуществом такого метода будет доступ к респонденту и заполняемость онлайн-формы. Деликатные вопросы (помимо сексуальной ориентации - употребление наркотиков, аборты, голосование и доход) приводят к наибольшему проценту неполученных ответов и подвержены влиянию

\footnotetext{
${ }^{6}$ Группы периодически блокируются по закону о пропаганде нетрадиционных сексуальных отношений.
} 
социальной желательности. Самостоятельно заполняемые анкеты позволяют чаще отвечать на них (Fenton et al.2001).

В нашем опросе респондентами были только представители ЛГБТ-сообщества, поэтому было важно оставить термин «сексуальная ориентация» в формулировке вопроса. При этом в качестве определения предлагали формулировки с точки зрения влечения, поскольку сами респонденты могут не относить себя к ЛГБТ-сообществу, не определять свою сексуальность с точки зрения идентичности. Вопрос был сформулирован следующим образом:

«Укажите Вашу сексуальную ориентацию:

- гомосексуальная (испытываете сексуальное влечение к людям своего пола; гей или лесбиянка);

- гетеросексуальная (испытываете сексуальное влечение к людям противоположного пола);

- бисексуальная (испытываете сексуальное влечение как к женщинам, так и к мужчинам);

- асексуальная (не испытываете сексуального влечения);

- пансексуальная (испытываете сексуальное влечение к людям, независимо от их пола, гендера или ориентации);

- другое».

Опрос был ориентрирован на людей с разными вариантами сексуальной ориентации и гендерной идентичности - было получено 873 ответа респондентов с отличной сексуальной и/или гендерной идентичностью. С точки зрения гендера (вопрос: «Совпадает ли Ваш биологический пол с гендером?») среди респондентов было $82 \%$ цисгендеров (биологический пол совпадает с гендером), 5,3\% указали, что их гендер может меняться, 2,7\% -что их пол не соответствует гендеру, 7,1\% - что не считают себя ни женщиной, ни мужчиной, 2,9\% выбрали вариант «другое» ${ }^{7}$. С точки зрения сексуальной ориентации $53 \%$ выбрали вариант «гомосексуальная», 21,8\% - «бисексуальная», 16,1\% - «пансексуальная», 3,1\% - «гетеросексуальная», 3\% - «асексуальная», 3\% - вариант «другое» ${ }^{8}$ В рамках данной статьи мы предлагаем рассмотреть только гомосексуалов (геев и лесбиянок, укоторых пол совпадает с гендером). Также были удалены ответы респондентов, которые на момент опроса уже не проживали в России. Итоговая выборка составила 390 респондентов, среди них 270 (69,2\%) мужчин (геев) и 120 (30,8\%) женщин (лесбиянок). Вероятно, на анкету ответили больше мужчин, так как большая часть групп, через которые распространялась анкета, имеет именно мужскую аудиторию. Поскольку анкета распространялась онлайн и все респонденты в гомосексуальной выборке завершили опрос, не представляется возможным оценить процент отказов (response rate). Также в

\footnotetext{
${ }^{7}$ Выбрав вариант «другое», респонденты указывали, что отрицают гендер, что допускают, что их гендер может меняться, а также «квир».

${ }^{8}$ Выбрав вариант «другое», респонденты имели возможность указать предпочитаемый вариант идентичности, среди них (25 ответов) были указаны такие варианты, как демисексуальная, гомоэротичная, гоморомантичная и квир (флюидная) идентичности в различных субъективных формулировках.
} 
итоговую выборку не попали респонденты, которые выбрали вариант «другое» в вопросе о сексуальной ориентации'.

Средний возраст респондентов - 26,7 года, стандартное отклонение - 7,34 (самому младшему респонденту 18 лет, старшему - 70).

В итоговой выборке 19,2\% неработающих студентов, 15,9\% работающих студентов, $3,8 \%$ имеют частичную занятость, $41,3 \%$ имеют полную занятость, $5,1 \%$ безработных в поиске работы, 1,8\% безработных, не ищущих работу, 12,8\% работают на себя (имеют собственный бизнес)/фрилансеров.

С точки зрения доходов распределение следующее: 2,3\% указали, что «денег не хватает даже на приобретение продуктов питания», 21,8\% - что «денег хватает на приобретение продуктов питания, но на одежду приходится откладывать», 42,3\% - что «денег достаточно для приобретения необходимых продуктов и одежды, более крупные покупки приходится откладывать», 25,9\% -что «денег достаточно для приобретения большинства товаров длительного пользования (холодильник, телевизор), но на покупку автомобиля приходится откладывать», 6,7\% - что «денег достаточно на совершение дорогостоящих покупок (автомобиль), но на покупку квартиры приходится откладывать» и только $1 \%$ указали, что «денег достаточно на любые покупки».

Около трети респондентов (31\%) проживают со своими партнерами, 26,9\% живут одни, $24 \%$ - с родителями и $17,4 \%$ - с друзьями.

На вопрос о ВИЧ-статусе (необязательный вопрос) ответили 387 респондентов из 390 , о положительном статусе сообщили 7,2\% респондентов из числа ответивших (все мужчины).

Для описания эффекта рождения (birth order effect) респондентам задавали вопрос о последовательности рождения братьев и/или сестёр в семье: $36,7 \%$ респондентов единственные дети своих родителей, остальные имеют братьев и сестер. При этом 33,8\% самые старшие дети в семье, $24,1 \%$ - вторые по порядку рождения, 3,8\% - третьи и 1,5\% четвертые. 1 респондент указал, что имеет брата-близнеца и 2 респондента указали, что имеют сестру-близнеца. Только 11 респондентов $(2,8 \%)$ указали, что имеют собственных детей.

С точки зрения сексуальной роли (ответили только 387 респондентов) 7,5\% респондентов указали «только пассивная», 32,8\% - «универсальная, но больше пассивная», 35,9\% - «универсальная», 19,6\% - «универсальная, но больше активная», 4,1\% - «только активная». Поскольку FBOE-исследования учитывают только мужчин, то рассмотрим далее выборку мужчин-гомосексуалов. В таблице 1 показан процент респондентов, которые являются единственными, старшими (Первый) и младшими

\footnotetext{
${ }^{9}$ Использование «другого» уменьшает размер выборки и снижает эффективность. Рекомендуется использовать варианты «Я еще не уверен»» и/или «Я не понимаю, что означает этот вопрос» (Saewyc et al. 2004). На наш взгляд, исследователям необходимо учитывать запросы сообщества при составлении анкет, но и ориентироваться на распространённые формулировки, чтобы не искажать выборку, если исследование не предполагает изучение иных идентичностей.
} 
(Второй, Третий, Четвертый) братьями (270 респондентов). Также выделим только тех респондентов, которые указали, что имеют братьев (124 респондента). За исключением единственных детей в семье, большее число респондентов - старшие братья (а не младшие, как предполагает FBOE); если выделить доли только среди братьев, то частично можно подтвердить предположения FВОЕ о том, что среди геев с пассивной сексуальной ролью больший процент младших братьев, но одновременно среди младших братьев также есть и геи с активной ролью (что противоречит исследованиям FBOE). На российской выборке мы не нашли подтверждения данного подхода: порядок рождения братьев не объясняет их сексуальную роль и ориентацию. Скорее стоит говорить об открытости и практиках камингаута, которые будут отличаться как по возрастным характеристикам, так и с точки зрения сексуальной позиции. Далее мы опишем процесс становления идентичности: принятия и осознания сексуальности.

Таблица 1. Доля мужчин-геев в последовательности рождения с точки зрения их сексуальной роли, \%

\begin{tabular}{|c|c|c|c|c|c|c|c|c|c|c|}
\hline \multirow[t]{2}{*}{$\begin{array}{l}\text { Очередность } \\
\text { рождения }\end{array}$} & \multicolumn{2}{|c|}{ Пассивная } & \multicolumn{2}{|c|}{$\begin{array}{c}\text { Универсально- } \\
\text { пассивная }\end{array}$} & \multicolumn{2}{|c|}{ Универсальная } & \multicolumn{2}{|c|}{$\begin{array}{c}\text { Универсально- } \\
\text { активная }\end{array}$} & \multicolumn{2}{|c|}{ Активная } \\
\hline & $\begin{array}{l}\text { среди } \\
\text { всех }\end{array}$ & $\begin{array}{l}\text { только } \\
\text { братья }\end{array}$ & $\begin{array}{l}\text { среди } \\
\text { всех }\end{array}$ & $\begin{array}{l}\text { только } \\
\text { братья }\end{array}$ & $\begin{array}{l}\text { среди } \\
\text { всех }\end{array}$ & $\begin{array}{l}\text { только } \\
\text { братья }\end{array}$ & $\begin{array}{l}\text { среди } \\
\text { всех }\end{array}$ & $\begin{array}{l}\text { только } \\
\text { братья }\end{array}$ & $\begin{array}{l}\text { среди } \\
\text { всех }\end{array}$ & $\begin{array}{l}\text { только } \\
\text { братья }\end{array}$ \\
\hline Единственный & 2,6 & 10,5 & 13,3 & 3,2 & 9,6 & 1,6 & 7,4 & 0,8 & 2,6 & 0,8 \\
\hline Первый & 4,1 & 0,8 & 12,2 & 17,7 & 9,3 & 14,5 & 5,9 & 9,7 & 1,1 & 0,8 \\
\hline Второй & 3,3 & 5,6 & 7,4 & 9,7 & 7,8 & 9,7 & 4,8 & 8,9 & 1,9 & 4,0 \\
\hline Третий & 0,4 & 3,2 & 2,2 & 4,0 & 1,5 & 1,6 & 0,7 & 1,6 & - & - \\
\hline Четвертый & 0,4 & 0,8 & - & - & - & - & 0,7 & 0,8 & - & - \\
\hline
\end{tabular}

Средний возраст осознания ориентации - 13,8 года (ст. отклонение $-3,9)$, при этом средний возраст принятия своей ориентации выше - 18,5 года (ст. отклонение 4,5). Далее рассмотрим отличительные особенности процесса, в том числе и через сексуальный дебют.

Средний возраст сексуального дебюта (вопрос можно было пропустить, в том числе, если ещё не было сексуального опыта) - 17,7 года, при этом первый гомосексуальный опыт в среднем наступает позже (средний возраст - 18,4 года).

Рассмотрим различия по возрасту, полу и сексуальной роли с точки зрения осознания, принятия и сексуального дебюта (таблицы 2,3,4). Более молодое поколение раньше осознаёт и раньше принимает свою сексуальную ориентацию. И в среднем процесс от осознания до принятия занимает 4,4 года, у старших поколений этот процесс занимал более 5 лет. Демографический сдвиг может быть связан со все более толерантным отношением среди молодёжи ${ }^{10}$. У мужчин от осознания до принятия ориентации проходит больше времени, чем у женщин. Но у женщин позже наступает (в среднем) как осознание, так и принятие гомосексуальности.

С точки зрения сексуальных ролей раньше всех осознают и принимают свою сексуальность респонденты, которые указали предпочтение пассивной сексуальной роли, позже - активной. Наиболее длительный процесс между осознанием и принятием у

\footnotetext{
${ }^{10} \mathrm{Cм.} \mathrm{обзор} \mathrm{изменения} \mathrm{общественного} \mathrm{мнения} \mathrm{и} \mathrm{исследование} \mathrm{отношения} \mathrm{к} \mathrm{гомосексуальности} \mathrm{среди}$ российских школьников (Tolkachev, Vasileva 2019).
} 
респондентов, предпочитающих универсально-активную роль (5,6 года). Следовательно, с точки зрения FBOE-подхода необходимо учитывать сложности процесса каминг-аута с учётом сексуальных ролей, когда, например, идентификация в качестве «актива» может быть связана с интернализованной гомофобией и проявлением стереотипного гендерного поведения (Hart et al. 2003).

Гомосексуальный дебют в среднем наступает после 18 лет. При этом сексуальный дебют в среднем наступает раньше. Следовательно, часть респондентов имели в том числе и гетеросексуальные практики. Также принятие ориентации может быть связано с гомосексуальным дебютом (в среднем возраст приятия происходит после гомосексуального опыта). То есть важно учитывать в исследованиях становления идентичности различный сексуальный опыт и его влияние на принятие гомосексуальности.

Таблица 2. Различие по возрасту с точки зрения осознания, принятия сексуальной ориентации и сексуального дебюта (средний возраст), лет

\begin{tabular}{l|c|c|c|c}
\hline Возраст & Осознание & Принятие & Сексуальный дебют & Гомосексуальный дебют \\
\hline $18-29$ & 13,4 & 17,8 & 17,6 & 18,2 \\
$30-39$ & 14,6 & 20,0 & 17,9 & 19,0 \\
$40+$ & 14,6 & 20,6 & 17,7 & 18,1 \\
\hline
\end{tabular}

Таблица 3. Различие по полу с точки зрения осознания, принятия сексуальной ориентации и сексуального дебюта (средний возраст), лет

\begin{tabular}{l|c|c|c|c}
\hline Пол & Осознание & Принятие & Сексуальный дебют & Гомосексуальный дебют \\
\hline Муж & 13,2 & 18,3 & 17,8 & 18,3 \\
Жен & 15,0 & 19,0 & 17,6 & 18,6 \\
\hline
\end{tabular}

Таблица 4. Различие по сексуальной роли с точки зрения осознания, принятия сексуальной ориентации и сексуального дебюта (средний возраст), лет

\begin{tabular}{l|c|c|c|c}
\hline Сексуальная роль & Осознание & Принятие & Сексуальный дебют & Гомосексуальный дебют \\
\hline Пассивная & 13,3 & 17,0 & 18,1 & 18,1 \\
Универсально-пассивная & 13,7 & 18,3 & 17,4 & 18,1 \\
Универсальная & 13,9 & 18,8 & 17,7 & 18,5 \\
Универсально-активная & 13,4 & 19,0 & 17,9 & 18,7 \\
Активная & 14,9 & 18,9 & 18,5 & 19,5 \\
\hline
\end{tabular}

Один из важных этапов становления идентичности - каминг-аут. С точки зрения публичного раскрытия идентичности ответы респондентов распределились следующим образом: 22,8\% не планируют совершать каминг-аут семье, 16,9\% не делали каминг-аут, но собираются его сделать. Почти половина $(48,7 \%)$ респондентов раскрыли свою сексуальную ориентацию отдельным членам семьи и $11,5 \%$ сделали каминг-аут для всех членов семьи. При этом 89,5\% респондентов совершали каминг-аут для гетеросексуальных друзей, $51 \%$ - среди знакомых, 48,2\% - среди коллег.

Здесь важно учитывать круг общения: только 21\% респондентов указали, что большинство их друзей являются представителями ЛГБТ-сообщества, 5,9\% указали, что среди их друзей вообще нет ЛГБТ (по крайней мере, насколько им это известно).

Только 27,4\% респондентов указали, что скорее отдают предпочтение в общении ЛГБТ-людям, а 1\% - что общаются исключительно с ЛГБТ-людьми. Для остальных сексуальная ориентация не имеет значения в формировании социальных связей. 
Рассмотрим далее взаимоотношения в семье. На вопрос об отношении с родственниками (таблица 5) 21,5\% отметили близкие отношения (высокая степень открытости) с матерью, только 3,3\% - с отцом, 3,6\% - с братьями и 9,7\% - с сёстрами (наиболее близкие или доверительные отношения с матерью, наиболее холодные с отцом).

\section{Таблица 5. Отношение с родственниками, \% респондентов}

\begin{tabular}{|c|c|c|c|c|}
\hline Отношения & Мать & Отец & Братья & Сестры \\
\hline 1 - Близкие (самая высокая степень открытости) & 21,5 & 3,3 & 3,6 & 9,7 \\
\hline 2 - Доверительные & 44,9 & 20,5 & 19,2 & 17,9 \\
\hline 3 - Нейтральные & 22,3 & 31,3 & 17,4 & 13,3 \\
\hline 4 - Безразличные & 2,8 & 11,5 & 5,4 & 5,1 \\
\hline 5 - Холодные (самая низкая степень открытости) & 5,1 & 14,4 & 3,3 & 1,3 \\
\hline 6 - Нет этого родственника & 3,3 & 19,0 & 51,0 & 52,6 \\
\hline
\end{tabular}

Также респонденты могли указать, считают ли они своих родственников (и каких именно) толерантными или гомофобными (таблица 6). Матери, сестры и бабушки более толерантны, чем отцы, братья и дедушки. С точки зрения негативного отношения большинство респондентов выдели родителей (больше отцов), в меньшей степени братьев и сестер. Раскрытие сексуальной ориентации чаще происходит в горизонтальных связях (братьям и сёстрам), а также женщинам, так как гендерные и возрастные факторы определяют толерантность (Hilton, Szymanski 2011).

Таблица 6. Субъективное восприятие толерантности и гомофобии в семьях, \% респондентов

\begin{tabular}{l|c|c}
\hline & Толерантные & Гомофобные \\
\hline Мать & 25,1 & 42,1 \\
Отец & 9,5 & 51,0 \\
Брат / братья & 10,0 & 11,3 \\
Сестра / сестры & 19,7 & 7,7 \\
Бабушки & 5,1 & 33,8 \\
Дедушки & 0,5 & 22,8 \\
\hline
\end{tabular}

При этом 38 респондентов указали, что в их семьях есть гомосексуальные родственники, при этом двое из них указали двух родственников (один респондент указал мать, двое - отца, 11 - братьев и сестер, 7 - дядь и тёть по материнской линии, 6 - дядь и тёть по отцовской линии и 13 - других родственников).

Также респондентам предлагали оценить степень гомофобии собственного окружения от 0 (наименее гомофобно) до 10 (наиболее гомофобно). Средняя оценка гомофобии - 3,5 (ст. отклонение 2,5). Респонденты, вероятно, пристально выбирают собственное окружение и стараются формировать круг общения, в котором люди наиболее толерантны к гомосексуальности (Herek, Glunt 1993). На похожий вопрос, но о гомофобии в стране, респонденты ответили иначе: гомофобию в РФ они оценили в среднем на 7,7 баллов (ст. отклонение - 1,5).

Принятие ориентации может быть осложнено насилием. Трое респондентов $(0,8 \%)$ проходили «лечение» сексуальной ориентации по собственному желанию, 5 (1,3\%) респондентов принуждали к прохождению «лечения», а 68 (17,4\%) респондентам предлагали такое лечение, но они отказались. В «решении» вопроса сексуальной 
ориентации 7 (1,8\%) респондентов прибегали к помощи религии по собственному желанию, четырёх (1\%) принуждали обратиться к религии, пятидесяти трем $(13,6 \%)$ предлагали решить вопрос ориентации при помощи религии, но они отказались.

На вопрос о насилии ответили 383 респондента (98,2\% всей выборки), из них 47\% указали, что не сталкивались с насилием, 35,2\% сталкивались только с психологическим насилием, 1,8\% -только с физическим насилием и 15,9\% - с обеими формами насилия; только 11 (менее 3\%) обращались в правоохранительные органы в связи с кейсами насилия. Большинство респондентов $(87,5 \%)$ не сталкивались с сексуальным насилием, при этом 7\% - жертвы гомосексуального насилия (из них 6,5\% мужчины), 4,7\% - жертвы гетеросексуального насилия (все - женщины), 3 (0,8\%) респондентки указали как гетеро-, так и гомосексуальное насилие. Также респонденты могли указать, были ли они знакомы с насильником, из 69 ответов (случаев насилия с учётом возможности указания нескольких вариантов) в 33 случаях это были незнакомые люди, в 27 случаях - знакомые, в 7 родственники, в 6 - друзья. Важнее скорее то, что только 2 респондента указали, что обращались в правоохранительные органы в связи с сексуальным насилием. Скорее всего, это связано с низким доверием власти (таблица 7): полиции $(86,2 \%)$, судам $(80,3 \%)$, законодательной власти $(90,5 \%)$ и правительству $(87,7 \%)$.

Таблица 7. Доверие органам власти, \% респондентов

\begin{tabular}{l|c|c|c|c}
\hline Степень доверия & Правительство & $\begin{array}{c}\text { Государственная } \\
\text { Дума и Совет } \\
\text { Федерации }\end{array}$ & Суды & Полиция \\
\hline Полностью не доверяю & 57,9 & 65,1 & 47,2 & 53,1 \\
Скорее не доверяю & 29,7 & 25,4 & 33,1 & 33,1 \\
Придерживаюсь нейтральной позиции & 10,8 & 8,5 & 15,1 & 11,3 \\
Скорее доверяю & 0,8 & 0,3 & 3,8 & 1,8 \\
Полностью доверяю & 0,8 & 0,8 & 0,8 & 0,8 \\
\hline
\end{tabular}

Дискриминация также может осложнять принятие ориентации и делать невозможным каминг-аут. Сталкивались с дискриминацией половина респондентов: 37,6\% указали, что это были единичные случаи, 10,7\% сталкиваются с дискриминацией регулярно и 2,9\% - постоянно. Не сталкивались с дискриминацией 50,7\% респондентов. В борьбе с дискриминацией страны могут вводить антидискриминационное законодательство (Ayoub 2016). Дискриминационное законодательство (запреты пропаганды или запреты однополых браков) могут негативно влиять на становление идентичности. Российский закон о «запрете пропаганды нетрадиционных сексуальных отношений среди несовершеннолетних» также может негативно влиять на ЛГБТ. Среди респондентов менее $1 \%$ не знают ничего о законе о пропаганде, $66,1 \%$ респондентов уверены, что хорошо знают положения закона и $35,2 \%$ знают о законе, но не знают его сути.

\section{ЗАКЛЮЧЕНИЕ}

Российская доля ЛГБТ может составлять около 10\% всего населения. Сексуальная ориентация при этом редко является объектом или переменной современных демографических исследований в России. Различные подходы к концептуализации сексуальной ориентации (как идентичности, поведения или влечения) требуют 
соответствующих формулировок в опросах. Выбор подхода будет влиять и на определение генеральной совокупности. В статье представлен обзор современных подходов к концептуализации и измерению сексуальной ориентации, а также описание демографических данных, полученных в ходе опроса российских гомосексуалов $(\mathrm{n}=390)$ с учётом ограничений онлайн-опроса, сложности определения генеральной совокупности и невероятнотностной выборки.

Целью статьи было описание демографических характеристик российских гомосексуалов, полученных при проведении опроса представителей ЛГБТ. Анализ данных позволил проследить общие тенденции демографии гомосексуальности. Российские гомосексуалы проходят характерные этапы от осознания до принятия идентичности, а также через процесс каминг-аута. Сексуальные практики играют важную роль в принятии гомосексуальной идентичности. Важно отметить, что в среднем гомосексуальный дебют наступает позже сексуального (т. е. для некоторых гетеросексуального) дебюта. Процесс формирования идентичности сложный и многогранный, поэтому требуется изучение различных сексуальных практик и исследование их влияния на идентичность. Сексуальные роли, связанные с гендерными стереотипами, также оказывают влияние на принятие сексуальной ориентации (и релевантны за пределами эссенциалистского подхода): среди мужчин воспринимаемая как более маскулинная (активная) роль связана с более длительным процессом принятия идентичности. Опрос позволил выявить возрастные и гендерные различия с точки зрения принятия и осознания ориентации: молодое поколение раньше осознаёт и быстрее принимает собственную гомосексуальную идентичность, а период между осознанием и принятием меньше у женщин, чем у мужчин, хотя в среднем эти события у женщин наступают позже. Большинство респондентов раскрывают собственную сексуальную идентичность среди близкого круга общения. Чаще всего каминг-аут совершают гетеросексуальным друзьям, знакомым и коллегам, чуть меньше половины - отдельным членам семьи. Гомосексуалы формируют близкий и доверительный круг общения, в том числе и в семьях. При этом низкий уровень доверия к власти и опыт дискриминации и насилия с минимальным обращением к государственным органам могут осложнять принятие ориентации и практики каминг-аута. Статья позволяет рассмотреть особенности жизни гомосексуалов в современных российских реалиях, что открывает новые возможности для исследований.

\section{БЛАГОДАРНОСТИ}

Выражаю сердечную признательность всем респондентам, сделавшим возможным проведение данного исследования, Варваре Васильевой, Ольге Малиновой, Никите Большакову, Валерии Якуткиной, Полине Хлыновой и, в особенности, Илье Гомыранову за моральную поддержку, вопросы и ценные замечания, а также двум анонимным рецензентам за критический взгляд, ценные комментарии и полезные рекомендации. 


\section{ЛИТЕРАТУРА}

Астрелин А.М. (2020). Тенденции заболеваемости, распространенности и смертности от ВИЧ-инфекции и туберкулеза в регионах России в XXI веке. Демографическое обозрение, 7(4), 82-107.

Градинари И. (Ред.) (2015). Техника "косого взгляда". Критика гетеронормативного порядка. Издательство Института Гайдара.

Гудкова Т.Б. (2019). Репродуктивные намерения россиян: мотивация и сдерживающие факторы. Демографическое обозрение, 6(4), 83-103.

Гурко Т.А. (2008). Брак и родительство в России. М.: Институт социологии РАН.

Демедецкая Я.А., Денисов Б.П., Лапицкая А.В. (2019). ВИЧ в транс*популяции: local case study. Демографическое обозрение, 6(3), 85-97.

Исупова О.Г. (2020). Демографическая и семейная политика в разных странах: концептуальные подходы и практики. Демографическое обозрение, 7(3), 51-83.

Кон И. (2010). Клубничка на березке. Сексуальная культура в России. М.: Время.

Кондаков А. (Ред.) (2014). На перепутье: методология, теория и практика ЛГБТ и квирисследований. СПб.: Центр независимых социологических исследований.

Мавлетова А.М. (2012). Мобильные веб-опросы. В Шашина А.В., Девятко И.Ф., Давыдова С.Г. (Ред.), Онлайн исследования в России 3.0. М.: Издательский дом «Кодекс»

Митрофанова Е.С. (2020). (Не)время взрослеть: как меняется возраст наступления дебютных биографических событий у россиян. Демографическое обозрение, 7(4), 3661.

Осипова И. (2020). Репродуктивные установки россиян и отношение к государственным мерам поддержки рождаемости. Демографическое обозрение, 7(2), 97-120.

Фуко М. (1996) Воля к истине: по ту сторону знания, власти и сексуальности. М.: Касталь.

Чурилова Е.В., Чумарина В.Ж. (2014). Внебрачные рождения и добрачные зачатия в России: осознанное решение родителей? Вопросы статистики, 7, 43-49.

Ayoub P. (2016). When States Come Out: Europe's Sexual Minorities and the Politics of Visibility. Cambridge: Cambridge University Press.

Ball C.A. (2001). Essentialism and Universalism in Gay Rights Philosophy: Liberalism Meets Queer Theory. Law \& Social Inquiry, 26(1), 271-293.

Bartle Ch. (2015). Gay/Queer Dynamics and the Question of Sexual History and Identity. Journal of Homosexuality, 62:4, 531-569.

Baumle A.K., Compton D.R., Poston D.L. (2009). Same-sex partners: The social demography of sexual orientation. Albany: State University of New York Press.

Baumle A.K., Poston D.L. (2011). The economic cost of being homosexual: A multilevel analysis. Social Forces, 89, 1005-1031.

Baumle A.K. (2013). Introduction: The Demography of Sexuality. In: Baumle A. (Eds.) International Handbook on the Demography of Sexuality. International Handbooks of Population, vol 5. Springer, Dordrecht. 
Black D., Gates G., Sanders S., Taylor L. (2000). Demographics of the gay and lesbian population in the United States: Evidence from available systematic data sources. Demography, 37, 139-154.

Blair J. (1999). A probability sample of gay urban males: The tale of two-phase adaptive sampling. Journal of Sex Research, 36, 39-44.

Blanchard R. (2018). Response to Commentaries: Meta-Analysis of Probability Samples and Other New Evidence. Archives of Sexual Behavior, 47(1), 49-57.

Butler J. (1997). The Psychic Life of Power: Theories in Subjection. Stanford, CA: Stanford University Press.

Butler J. (2006). Gender Trouble: Feminism and the Subversion of Identity. New York: Routledge Classics.

Cass V.C. (1984). Homosexual Identity Formation: Testing a Theoretical Model. The Journal of Sex Research, 20(2), 143-167

Crawley S.L., Broad K.L. (2008). The Construction of Sex and Sexualities. In J.A. Holstein, J.F. Gubrium (Eds), Handbook of Constructionist Research (pp.545-566). New York: The Guilford Press.

Diamond M. (1993). Homosexuality and bisexuality in different populations. Archives of Sexual Behavior, 22, 291-310.

Drucker D.J. (2010). Male Sexuality and Alfred Kinsey's 0-6 Scale: Toward "A Sound Understanding of the Realities of Sex". Journal of Homosexuality, 57:9, 1105-1123

Durso L.E., Gates G.J. (2013). Best Practices: Collecting and Analyzing Data on Sexual Minorities. In A. Baumle (Eds), International Handbook on the Demography of Sexuality. International Handbooks of Population, vol 5. Springer, Dordrecht.

Eliason M.J., Schope R. (2007). Shifting sands or solid foundation? Lesbian, gay, bisexual, and transgender identity formation. In I.H. Meyer, M.E. Northridge (Eds.), The health of sexual minorities: Public health perspectives on lesbian, gay, bisexual and transgender populations (pp. 3-26). New York: Springer.

Fenton K.A., Johnson A.M., McManus S., Erens B. (2001). Measuring sexual behavior: Methodological challenges in survey research. Sexually Transmitted Infections, 77, 84-92.

Festy P. (2006). Legal recognition of same-sex couples in Europe. Population, 61, 417-453

Grov C., Parsons J.T. Bimbi D.S. (2010). The Association Between Penis Size and Sexual Health Among Men Who Have Sex with Men. Archives of Sexual Behavior, 39, 788-797.

Halwani R. (1998). Essentialism, Social Constructionism, and the History of Homosexuality. Journal of Homosexuality, 35(1), 25-51.

Hart T.A., Wolitski R.J., Purcell D.W., Gòmez C., Halkitis P., The Seropositive Urban Men's Study Team (2003). Sexual behavior among HIV-positive men who have sex with men: What's in a label? Journal of Sex Research, 40, 179-188

Herek G.M., Glunt E.K. (1993). Interpersonal contact and heterosexuals' attitudes toward gay men: Results from a national survey. Journal of Sex Research, 30(3), 239-244.

Hilton A.N., Szymanski D.M. (2011). Family Dynamics and Changes in Sibling of Origin Relationship After Lesbian and Gay Sexual Orientation Disclosure. Contemporary Family Therapy, 33, 291. 
Laumann E.O., Gagnon J.H., Michael R.T., Michaels S. (1994). The social organization of sexuality: Sexual practices in the U.S. Chicago: University of Chicago Press.

Makarychev A., Medvedev S. (2015). Biopolitics and Power in Putin's Russia. Problems of Post-Communism, 62 (1): 45-54

Martin L. (2015). The Family in Flux: Changing Sexual and Reproductive Practices. In: DeLamater J., Plante R. (Eds) Handbook of the Sociology of Sexualities. Handbooks of Sociology and Social Research. Springer, Cham.

Meyer I.H., Northridge M.E. (2007). The health of sexual minorities: Public health perspectives on lesbian, gay, bisexual and transgender populations. New York: Springer.

Meyer I.H., Wilson P.A. (2009). Sampling lesbian, gay, and bisexual populations. Journal of Counseling Psychology, 56(1), 23-31.

Milton H.L., MacDonald G.J. (1984). Homosexual Identity Formation as a Developmental Process. Journal of Homosexuality, 9(2-3), 91-104.

Nartova N. (2007). "Russian Love", or What of Lesbian Studies in Russia? Journal of Lesbian Studies, 11(3-4), 313-320.

Pachankis J.E., Buttenwieser I.G., Bernstein L.B. et al. (2013). A Longitudinal, Mixed Methods Study of Sexual Position Identity, Behavior, and Fantasies Among Young Sexual Minority Men. Archives of Sexual Behavior, 42, 1241-1253.

Poston D., Chang Y.T. (2015). The Conceptualization and Measurement of the Homosexual, Heterosexual, and Bisexual Populations in the United States. In: Hoque M., B. Potter L. (Eds) Emerging Techniques in Applied Demography. Applied Demography Series, vol 4. Springer, Dordrecht.

Riabov O., Riabova T. (2014). The Remasculinization of Russia? Problems of Post-Communism, $61(2), 23-35$.

Saewyc E.M., Bauer G.R., Skay C.L., Bearinger L.H., Resnick M.D., Reis E., Murphy A. (2004). Measuring sexual orientation in adolescent health surveys: Evaluation of eight school-based surveys. Journal of Adolescent Health, 35(4), 345.E1-345.E15.

Sell R. (2007). Defining and measuring sexual orientation for research. In I.H. Meyer, M.E. Northridge (Eds.), The health of sexual minorities: Public health perspectives on lesbian, gay, bisexual and transgender populations (pp. 355-374). New York: Springer.

Singer B., Deschamps D. (2017). LGBTQ Stats: Lesbian, Gay, Bisexual, Transgender, and Queer People by the Numbers. NY: The New Press.

Stella F. (2015). Lesbian Lives in Soviet and Post-Soviet Russia. Post/Socialism and Gender Sexualities. Basingstoke: Palgrave Macmillan.

Tolkachev D.S., Vasileva V.M. (2019). Social landscapes: A conservative turn for Russian gender and sexuality education. In T. Jones, L. Coll, L. van Leent, Y. Taylor (Eds.), Uplifting Gender and Sexuality Education Research. Palgrave Studies in Gender and Education. Cham: Palgrave Macmillan.

Vrangalova Z., Savin-Williams R.C. (2012). Mostly Heterosexual and Mostly Gay/Lesbian: Evidence for New Sexual Orientation Identities. Archives of Sexual Behavior, 41, 85-101.

Wampold C.H. (2018). Volvivity, Femininity, Fraternity: Breaching the Sexual Orientation Fortress. Archives of Sexual Behavior, 47(1), 43-46. 
Wei C., Raymond H.F. (2011). Preference for and Maintenance of Anal Sex Roles Among Men Who Have Sex with Men: Sociodemographic and Behavioral Correlates. Archives of Sexual Behavior, 40, 829-834.

Wilkinson C. (2014). Putting 'traditional values' into practice: The rise and contestation of antihomopropaganda laws in Russia. Journal of Human Rights, 13(3), 363-379.

Zdravomyslova E., Temkina A. (2012). The Crisis of Masculinity in Late Soviet Discourse. Russian Studies in History, 51 (2), 13-34. 


\section{FEATURES OF SEXUAL ORIENTATION STUDIES: DEMOGRAPHIC CHARACTERISTICS OF RUSSIAN HOMOSEXUALS}

\section{DMITRII TOLKACHEV}

In demography, sexual behavior is considered as one of the types of demographic behavior. Sexual orientation is the broadest term, encompassing several different conceptual approaches on which the design of a study depends. Sexual behavior, sexual identity, and sexual attraction require different research approaches and different measurement methods.

The article provides an overview of modern approaches to the conceptualization and measurement of sexual orientation, as well as a description of the demographic data obtained in a survey of Russian homosexuals $(n=390)$.

There are three main approaches to the study of sexuality in the social sciences: essentialist, constructivist, and queer. These approaches differ in their understanding of the origins of (homo)sexuality and in their interpretation of orientation (as identity, behavior, or attraction). The article offers options for the formulation of questions for measuring sexual orientation in the framework of the three approaches, as well as an overview of methodological limitations - the problems of sampling and determining the general population.

The article presents the results of a Russian LGBT survey and describes the data on Russian homosexuals (gays and lesbians). The data obtained make it possible to describe the age of awareness and acceptance of sexual orientation, the age of sexual debut, the experience of coming out to relatives, friends and colleagues, relationships with relatives, the experience of violence and discrimination, and trust in the authorities.

Key words: sexual orientation, LGBT, homosexuality, demography of sexuality, queer, Russian homosexuals.

DMitri Tolkachev (dtolkachev@hse.ru), NATIONAL RESEARCh University Higher School of Economics, RUSSIA.

DATE RECEIVED : MAY 2021.

\section{REFERENCES}

Astrelin A. (2020). Trends in morbidity, prevalence and mortality from HIV infection and tuberculosis in the regions of Russia in the XXI century. Demographic Review, 7(4), 82-107. (In Russ.).

Ayoub P. (2016). When States Come Out: Europe's Sexual Minorities and the Politics of Visibility. Cambridge: Cambridge University Press.

Ball C.A. (2001). Essentialism and Universalism in Gay Rights Philosophy: Liberalism Meets Queer Theory. Law \& Social Inquiry, 26(1), 271-293.

Bartle Ch. (2015). Gay/Queer Dynamics and the Question of Sexual History and Identity. Journal of Homosexuality, 62, 4, 531-569.

Baumle A.K., Compton D.R., Poston D.L. (2009). Same-sex partners: The social demography of sexual orientation. Albany: State University of New York Press. 
Baumle A.K., Poston D.L. (2011). The economic cost of being homosexual: A multilevel analysis. Social Forces, 89, 1005-1031.

Baumle A.K. (2013). Introduction: The Demography of Sexuality. In Baumle A. (Ed.), International Handbook on the Demography of Sexuality. International Handbooks of Population, vol 5. Springer, Dordrecht.

Black D., Gates G., Sanders S., Taylor L. (2000). Demographics of the gay and lesbian population in the United States: Evidence from available systematic data sources. Demography, 37, 139-154.

Blair J. (1999). A probability sample of gay urban males: The tale of two-phase adaptive sampling. Journal of Sex Research, 36, 39-44.

Blanchard R. (2018). Response to Commentaries: Meta-Analysis of Probability Samples and Other New Evidence. Archives of Sexual Behavior, 47(1), 49-57.

Butler J. (1997). The Psychic Life of Power: Theories in Subjection. Stanford, CA: Stanford University Press.

Butler J. (2006). Gender Trouble: Feminism and the Subversion of Identity. New York: Routledge Classics.

Cass V.C. (1984). Homosexual Identity Formation: Testing a Theoretical Model. The Journal of Sex Research, 20(2), 143-167.

Churilova E, Chumarina V. (2014). Nonmarital fertility and premarital conceptions in Russia: parents' deliberate decision? Voprosy statistiki, 7, 43-49. (In Russ.)

Crawley S.L., Broad K.L. (2008). The Construction of Sex and Sexualities. In J.A. Holstein, J.F. Gubrium (Eds), Handbook of Constructionist Research (pp. 545-566). New York: The Guilford Press.

Demedetskaya Y., Denisov B., Lapitskaya A. (2019). HIV in trans*population: local case study. Demographic Review, 6(3), 85-97. (In Russ.).

Diamond M. (1993). Homosexuality and bisexuality in different populations. Archives of Sexual Behavior, 22, 291-310.

Drucker D.J. (2010). Male Sexuality and Alfred Kinsey's 0-6 Scale: Toward “A Sound Understanding of the Realities of Sex". Journal of Homosexuality, 57:9, 1105-1123.

Durso L.E., Gates G.J. (2013). Best Practices: Collecting and Analyzing Data on Sexual Minorities. In A. Baumle (Ed.), International Handbook on the Demography of Sexuality. International Handbooks of Population, vol 5. Springer, Dordrecht.

Eliason M.J., Schope R. (2007). Shifting sands or solid foundation? Lesbian, gay, bisexual, and transgender identity formation. In I.H. Meyer, M.E. Northridge (Eds.), The health of sexual minorities: Public health perspectives on lesbian, gay, bisexual and transgender populations (pp. 3-26). New York: Springer.

Fenton K.A., Johnson A.M., McManus S., Erens B. (2001). Measuring sexual behavior: Methodological challenges in survey research. Sexually Transmitted Infections, 77, 84-92.

Festy P. (2006). Legal recognition of same-sex couples in Europe. Population, 61, 417-453.

Fuko M. (1996). Volya k istine: po tu storonu znaniya, vlasti i seksual'nosti [The Will to Truth: beyond Knowledge, Power and sexuality]. Moscow: Kastal'. (In Russ.). 
Gradinari I. (Ed.) (2015). Tekhnika "kosogo vzglyada". Kritika geteronormativnogo poryadka [The technique of "oblique gaze". Criticism of the heteronormative order]. Izdatel'stvo Instituta Gaydara. (In Russ.).

Grov C., Parsons J.T., Bimbi D.S. (2010). The Association Between Penis Size and Sexual Health Among Men Who Have Sex with Men. Archives of Sexual Behavior, 39, 788-797.

Gudkova T. (2019). Fertility intentions in Russia: motivation and constraints. Demographic Review, 6(4), 83-103. (In Russ.).

Gurko T.A. (2008). Brak i roditel'stvo v Rossii [Marriage and parenthood in Russia]. Moscow: Institut sotsiologii RAN. (In Russ.).

Halwani R. (1998). Essentialism, Social Constructionism, and the History of Homosexuality. Journal of Homosexuality, 35(1), 25-51.

Hart T.A., Wolitski R.J., Purcell D.W., Gòmez C., Halkitis P., The Seropositive Urban Men's Study Team (2003). Sexual behavior among HIV-positive men who have sex with men: What's in a label? Journal of Sex Research, 40, 179-188

Herek G.M., Glunt E.K. (1993). Interpersonal contact and heterosexuals' attitudes toward gay men: Results from a national survey. Journal of Sex Research, 30(3), 239-244.

Hilton A.N., Szymanski D.M. (2011). Family Dynamics and Changes in Sibling of Origin Relationship After Lesbian and Gay Sexual Orientation Disclosure. Contemporary Family Therapy, 33, 291.

Isupova O. (2020). Population and family policy in different countries: conceptual approaches and practices. Demographic Review, 7(3), 51-83. (In Russ.).

Kon I. (2010). Klubnichka na berezke. Seksual'naya kul'tura v Rossii [Strawberry on a birch tree. Sexual culture in Russia]. Moscow: Vremya. (In Russ.).

Kondakov A. (2014). Na pereput'ye: metodologiya, teoriya i praktika LGBT i kvir-issledovaniy [At the crossroads: methodology, theory and practice of LGBT and Queer Studies]. SPb.: Tsentr nezavisimykh sotsiologicheskikh issledovaniy. (In Russ.).

Laumann E.O., Gagnon J.H., Michael R.T., Michaels S. (1994). The social organization of sexuality: Sexual practices in the U.S. Chicago: University of Chicago Press.

Makarychev A., Medvedev S. (2015). Biopolitics and Power in Putin's Russia. Problems of Post-Communism, 62 (1): 45-54

Martin L. (2015). The Family in Flux: Changing Sexual and Reproductive Practices. In DeLamater J., Plante R. (Eds), Handbook of the Sociology of Sexualities. Handbooks of Sociology and Social Research. Springer, Cham.

Mavletova A.M. (2012). Mobil'nyye veb-oprosy [Mobile web surveys]. In Shashina A.V., Devyatko I.F., Davydova S.G. (Red.), Onlayn issledovaniya v Rossii 3.0.Moscow [Online research in Russia 3.0.]: Izdatel'skiy dom «Kodeks». (In Russ.).

Meyer I.H., Northridge M.E. (2007). The health of sexual minorities: Public health perspectives on lesbian, gay, bisexual and transgender populations. New York: Springer.

Meyer I.H., Wilson P.A. (2009). Sampling lesbian, gay, and bisexual populations. Journal of Counseling Psychology, 56(1), 23-31.

Milton H.L., MacDonald G.J. (1984). Homosexual Identity Formation as a Developmental Process. Journal of Homosexuality, 9(2-3), 91-104. 
Mitrofanova E. (2020). (No)time to grow up: changing ages of debut biographical events in Russia. Demographic Review, 7(4), 36-61. (In Russ.).

Nartova N. (2007). "Russian Love", or What of Lesbian Studies in Russia? Journal of Lesbian Studies, 11 (3-4), 313-320.

Osipova I. (2020). Reproductive attitudes of Russians and how they regard government measures to support fertility. Demographic Review, 7(2), 97-120. (In Russ.).

Pachankis J.E., Buttenwieser I.G., Bernstein L.B. et al. (2013). A Longitudinal, Mixed Methods Study of Sexual Position Identity, Behavior, and Fantasies Among Young Sexual Minority Men. Archives of Sexual Behavior, 42, 1241-1253.

Poston D., Chang Y.T. (2015). The Conceptualization and Measurement of the Homosexual, Heterosexual, and Bisexual Populations in the United States. In: Hoque M., B. Potter L. (eds) Emerging Techniques in Applied Demography. Applied Demography Series, vol 4. Springer, Dordrecht.

Riabov O., Riabova T. (2014). The Remasculinization of Russia? Problems of Post-Communism, $61(2), 23-35$.

Saewyc E.M., Bauer G.R., Skay C.L., Bearinger L.H., Resnick M.D., Reis E., Murphy A. (2004). Measuring sexual orientation in adolescent health surveys: Evaluation of eight school-based surveys. Journal of Adolescent Health, 35(4), 345.E1-345.E15.

Sell R. (2007). Defining and measuring sexual orientation for research. In I.H. Meyer, M. E. Northridge (Eds.), The health of sexual minorities: Public health perspectives on lesbian, gay, bisexual and transgender populations (pp. 355-374). New York: Springer.

Singer B., Deschamps D. (2017). LGBTQ Stats: Lesbian, Gay, Bisexual, Transgender, and Queer People by the Numbers. NY: The New Press.

Stella F. (2015). Lesbian Lives in Soviet and Post-Soviet Russia. Post/Socialism and Gender Sexualities. Basingstoke: Palgrave Macmillan.

Tolkachev D.S., Vasileva V.M. (2019). Social landscapes: A conservative turn for Russian gender and sexuality education. In T. Jones, L. Coll, L. van Leent, Y. Taylor (Eds.), Uplifting Gender and Sexuality Education Research. Palgrave Studies in Gender and Education. Cham: Palgrave Macmillan.

Vrangalova Z., Savin-Williams R.C. (2012). Mostly Heterosexual and Mostly Gay/Lesbian: Evidence for New Sexual Orientation Identities. Archives of Sexual Behavior, 41, 85-101.

Wampold C.H. (2018). Volvivity, Femininity, Fraternity: Breaching the Sexual Orientation Fortress. Archives of Sexual Behavior, 47(1), 43-46.

Wei C., Raymond H.F. (2011). Preference for and Maintenance of Anal Sex Roles Among Men Who Have Sex with Men: Sociodemographic and Behavioral Correlates. Archives of Sexual Behavior, 40, 829-834.

Wilkinson C. (2014). Putting 'traditional values' into practice: The rise and contestation of antihomopropaganda laws in Russia. Journal of Human Rights, 13(3), 363-379.

Zdravomyslova E., Temkina A. (2012). The Crisis of Masculinity in Late Soviet Discourse. Russian Studies in History, 51 (2), 13-34. 